\title{
CHARACTERISATION AND ANTIFUNGAL SUSCEPTIBILITY TESTING OF CANDIDA SPECIES ISOLATED FROM CLINICAL SAMPLES OF PATIENTS ATTENDING KATIHAR MEDICAL COLLEGE, KATIHAR, BIHAR
}

\author{
Sagar Kumar1, Sangeeta Dey², Anindo Sen³, Dhananjaya Kumar, Kahakashan Akhter ${ }^{5}$ \\ 1 Final Year Postgraduate Student, Department of Microbiology, Katihar Medical College, Katihar. \\ 2 Professor and HOD, Department of Microbiology, Katihar Medical College, Katihar. \\ 3 Professor, Department of Microbiology, Katihar Medical College, Katihar. \\ ${ }_{4}^{4}$ Assistant Professor, Department of Microbiology, Katihar Medical College, Katihar. \\ ${ }_{5}^{5}$ Assistant Professor, Department of Microbiology, Katihar Medical College, Katihar.
}

\begin{abstract}
\section{BACKGROUND}

Of the various candida species, more than $90 \%$ of invasive infections are caused by Candida albicans, Candida glabrata, Candida parapsilosis, Candida tropicalis, Candida krusei, Candida dubliniensis and Candida lusitaniae. Clinical manifestations range from mucocutaneous overgrowth to disseminated infections like candidaemia. Virulence factors like tissue adhesion, phenotypic switching and production of extracellular hydrolytic enzymes are responsible for colonisation and invasion of host tissues along with host factors like immunocompromised states.

The aim of this study is to characterise candida strains isolated from patients and to study their anti-fungal susceptibility pattern.
\end{abstract}

\section{MATERIALS AND METHODS}

Samples such as pus, sputum, blood and urine were collected from patients attending OPD's and IPD's of Medicine, Surgery, Obstetrics and Gynaecology, Paediatrics and Casualty. In this study, primary isolation was done on blood and Sabouraud's dextrose agar from clinical samples. Species were identified based on production of coloured colonies on HiCrome agar and other phenotypic tests like germ tube and chlamydospores formation, sugar fermentation and assimilation tests. Statistical AnalysisStatistical analysis was carried out using online statistical software at http://www.physics.csbsju .edu/stats/contingency_NROW_NCOLUMN_form.html. Chi-square test was used to determine the probability.

Study Design- This descriptive study was conducted in the Department of Microbiology, Katihar Medical College, Katihar, Bihar.

\section{RESULTS}

Candida species isolated were Candida albicans $38.5 \%$ followed by Candida famata $22.2 \%$, Candida guilliermondii $17 \%$, Candida tropicalis 6.7\%, Candida kefyr 5.2\%, Candida dubliniensis 3\%, Candida glabrata and Candida parapsilosis 2.2\% each and Candida lusitaniae and Candida catenulata 1.5\% each. Modified Kirby Bauer's Disc Diffusion method was used for performing anti-fungal susceptibility tests. Candida albicans and non-albicans candida were most sensitive to voriconazole $(73.1 \%$ and $84.3 \%)$ and most resistant to miconazole ( $51.9 \%$ and $66.3 \%$ respectively).

\section{CONCLUSION}

Candida albicans was the most frequently isolated species in the present study. Candida species was isolated most frequently from urine samples followed by vaginal swab and sputum. Highest number of candidiasis patients were from Departments of Obstetrics and Gynaecology 57.0\% followed by Paediatrics $17.8 \%$ and Medicine 14.1\%. Candida albicans was the most commonly isolated candida species, 38.5\%. Maximum number of Candida albicans strains showed dose-dependent sensitivity with nystatin $76.9 \%$. NAC species showed resistance to miconazole $66.3 \%$ followed by ketoconazole $47 \%$ and fluconazole $25.03 \%$.

\section{KEYWORDS}

Candida Albicans, Non-Albicans Candida, Anti-Fungal Susceptibility.

HOW TO CITE THIS ARTICLE: Kumar S, Dey S, Sen A, et al. Characterisation and antifungal susceptibility testing of candida species isolated from clinical samples of patients attending Katihar Medical College, Katihar, Bihar. J. Evolution Med. Dent. Sci. 2018;7(05): 662-666, DOI: $10.14260 /$ jemds/2018/150

\begin{tabular}{|c|}
\hline $\begin{array}{l}\text { BACKGROUND } \\
\text { Candida is one of the frequently } \\
\text { fungal pathogen, which is associa } \\
\text { human infections. Candida coloniz } \\
\text { in recent times there is an increase }\end{array}$ \\
\hline 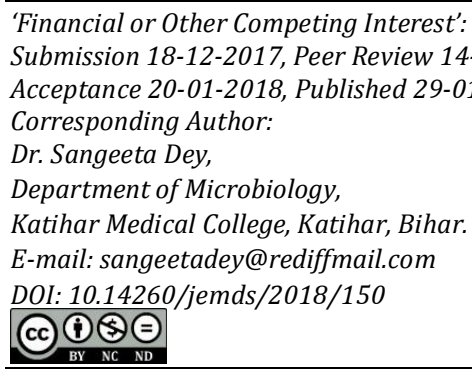 \\
\hline
\end{tabular}
albicans candida (NAC). ${ }^{1}$ NAC species are currently more frequently recovered from adults and children in tertiary care medical centres and there are numerous reports on increase of Candida infection from India as well. ${ }^{2}$ At present there are 163 acknowledged anamorphic species of the genus candida, which are found in different habitats. The increase in the incidence of candida species over the past two decades is significant and NAC species continue to replace Candida albicans at most of the clinical sites like the blood stream. Now, candida species constitutes the third to fourth most common causes of nosocomial bloodstream infections. ${ }^{3}$

Candida species can cause a wide range of infections including blood stream infections (BSIs) and disseminated candidiasis. In spite of advances in the diagnosis and 
treatment of candidiasis, among the pathogens involved in BSI candida ranks fourth in the United States and seventh in Europe. ${ }^{4-7}$ Few studies from India have reported candidaemia rates of $6 \%-18 \%^{8-10}$ and increase in isolation of NAC from BSIs. 11,12 In a recent study, the incidence rate of candidaemia has been reported to be 6.9 per 1000 in intensive care unit (ICU) patients, and $7.5 \%$ of ICU patients receiving antifungal therapy. ${ }^{13,14}$ Candidaemia increases mortality rate by $20 \%$ $49 \% 15,16$ and nosocomial candidiasis are associated with crude mortality rate of over $60 \%$, while the attributable mortality rate may be as high as $49 \% .17,18$

Antifungal agents available for the treatment of systemic and invasive candidiasis are restricted to polyenes, allylamines, azoles and the recently developed echinocandin class of molecules. Fluconazole is an antifungal agent most commonly used for prophylaxis, as it can be administered orally and is comparatively cheaper than other antifungal agents. Nonetheless, selection of appropriate empiric therapy is complicated considering the increasing prevalence of NAC species. ${ }^{19}$

The present study was undertaken to determine the rate of isolation of candida species from different clinical samples, to characterise the isolates and determine their antifungal susceptibility pattern. The study was conducted from December 2015 to May 2017.

\section{MATERIALS AND METHODS}

A brief clinical history of patient including age, sex, socioeconomic status, religion, history of intake of antibiotics/ antifungal agents and past history were taken. A total of one hundred and thirty five candida species were isolated from 54 male and 81 female patients attending or admitted to the Departments of Medicine, Surgery, Obstetrics and Gynaecology, Paediatrics and Casualty. Wound, vaginal, oral and aural samples were collected with the help of sterile swab sticks. Mid-stream early morning urine samples were collected in sterile containers. Blood samples were collected for culture in blood culture bottles and sputum samples in sterile containers. ${ }^{19}$

$10 \% \mathrm{KOH}$ mounts and Gram stained smears were made from samples and examined for presence of yeast like cells with or without pseudohyphae. Specimens were inoculated on routine culture media and Sabouraud's dextrose agar. Blood culture was done by incubation of inoculated blood culture bottles containing brain heart infusion broth at $37^{\circ} \mathrm{C}$ and open subcultures were done on blood agar and SDA after 24 hrs., 48 hrs. and 7 days of incubation. Bottles showing no growth after 7 days of incubation were discarded as negative. ${ }^{19}$

For identification of candida species, HiCrome agar (HiMedia Laboratories, Mumbai) plates were inoculated with the test strain and incubated at $37^{\circ} \mathrm{C}$ for 24 to 48 hours. The appearance of colonies of various colours was then noted down. Commercially available corn meal agar with $1 \%$ Tween 80 was prepared and inoculated with the test strain. Plates were incubated at $25^{\circ} \mathrm{C}$ for 3 - 5 days following which morphological features like hyphae, pseudohyphae, blastospores and chlamydospores formation of various candida species was observed microscopically for differentiation of Candida albicans from non-albicans candida species. ${ }^{20}$ Germ tube Test, Sugar Fermentation Tests (glucose, lactose, maltose and sucrose) and Sugar Assimilation Test was done as confirmatory tests for characterisation and identification of candida species against panel of sugars. ${ }^{19}$ Antifungal Susceptibility Testing by Kirby-Bauer disc diffusion method was done using Mueller-Hinton agar, 2\% glucose and $(0.5 \mu \mathrm{g} / \mathrm{mL})$ methylene blue dye. Zone size interpretation of various candida species against amphotericin B (100 $\mu \mathrm{g})$, voriconazole $(1 \mu \mathrm{g})$, fluconazole (25 $\mu \mathrm{g})$, itraconazole $(10 \mu \mathrm{g})$, ketoconazole $(10 \mu \mathrm{g})$, miconazole $(30 \mu \mathrm{g})$ and nystatin (100 units) was done as per standard protocol.20

Statistical analysis was carried out using online statistical software at http:// http://www.physics.csbsju.edu/stats/contingency_NROW_N COLUMN_form.html. Chi-square test was used to determine the probability.

\section{RESULTS}

A total of one hundred and thirty five candida strains were isolated in the Department of Microbiology from December 2015 to May 2017 from various samples, which were taken up for further study. Institutional Ethical Committee clearance and written consent was obtained from each and every patient before conducting the study.

Out of the 135 patients from whom candida species was isolated, $60.0 \%$ were females and $40.0 \%$ were males. In age group of 21 - 30 years the occurrence of candida infections was more in females, a finding that was found to be statistically highly significant $(p=0.000)$. As for male patients, these infections were most frequently encountered in the age group of 1 - 10 years, which was also found to be highly significant $(p=0.003)$. Overall, in the present study the female-to-male ratio was 1.5: 1 (Table 1).

Candida species were isolated from urine $36.3 \%$, vaginal swab $18.5 \%$, sputum $17.0 \%$, wound swab $11.9 \%$, blood $8.9 \%$, oral swab $4.4 \%$ and aural swab 3.0\% (Table 2).

Highest number of candidiasis patients were from Department of Obstetrics and Gynaecology 57.0\% followed by Paediatrics $17.8 \%$ and Medicine $14.1 \%$. Candida albicans was the most commonly isolated candida species $38.5 \%$. Amongst the non-albicans candida sp. that was isolated, Candida famata $22.2 \%$ was the commonest followed by Candida guilliermondii 17\%, Candida tropicalis $6.7 \%$, Candida kefyr 5.2\%, Candida dubliniensis $3.0 \%$, Candida glabrata and Candida parapsilosis $2.2 \%$ each and Candida lusitaniae and catenulata $1.5 \%$ each (Fig. 1).

Microscopic examination of Gram stained smears and $10 \% \mathrm{KOH}$ mount showed yeast like cells with or without pseudohyphae in $59.3 \%$ and $63 \%$ of cases respectively. Germ tube formation was seen in $96.2 \%$ of Candida albicans, $33.3 \%$ of Candida famata and $17.4 \%$ of Candida guilliermondii. All the strains of Candida dubliniensis were positive in the germ tube test. Chlamydospore formation was seen in only $38.5 \%$ of Candida albicans and $10 \%$ and $8.6 \%$ of Candida famata and Candida guilliermondii respectively.

Typical reactions in the Sugar Assimilation Test were seen in only $96.2 \%$ of Candida albicans, $90 \%$ of Candida famata, $88.9 \%$ of Candida tropicalis and $87 \%$ of Candida guilliermondii. All the other species of candida gave typical reaction in $100 \%$ of cases.

All candida species were confirmed on the basis of sugar fermentation test and sugar assimilation test. The sugar assimilation test was found to be the best test for speciation 
of candida. However, as far as Candida albicans is concerned, the germ tube test was found to be as sensitive as the sugar assimilation test.

Candida albicans strains were most sensitive to voriconazole $73.1 \%$ followed by fluconazole $63.5 \%$ and amphotericin B 61.5\%. Maximum number of strains showed dose dependent sensitivity with nystatin $76.9 \%$. Maximum resistance was seen with miconazole $51.9 \%$ followed by ketoconazole $40.4 \%$ and fluconazole $34.6 \%$. Dose dependent susceptibility was most commonly encountered with nystatin $71.1 \%$ followed by itraconazole $43.4 \%$ and ketoconazole $31.3 \%$ (Table 3). NAC species too showed maximum sensitivity to voriconazole was $84.3 \%$ followed by amphotericin B 71.1\% and fluconazole $65.1 \%$. Majority of the strains NAC showed resistance to miconazole $66.3 \%$ followed by ketoconazole $47 \%$ and fluconazole $25.03 \%$ (Table 4 ).

\begin{tabular}{|c|c|c|c|}
\hline $\begin{array}{l}\text { Age Group } \\
\text { (Years) }\end{array}$ & Male (\%) & Female (\%) & Total \\
\hline $1-10^{*}$ & $21(38.9)$ & $9(11.1)$ & $30(22.2)$ \\
\hline $11-20$ ** & $2(03.7)$ & 15 (18.5) & $17(12.6)$ \\
\hline $21-30^{* * *}$ & $5(09.3)$ & $39(48.1)$ & $44(32.6)$ \\
\hline $31-40$ & $3(05.6)$ & $13(16.0)$ & $16(11.9)$ \\
\hline $41-50$ & $5(09.3)$ & $1(01.2)$ & $06(04.4)$ \\
\hline $51-60$ & 8 (14.8) & 0 & $08(05.9)$ \\
\hline $61-70$ & $8(14.8)$ & $2(02.5)$ & $10(13.5)$ \\
\hline $71-80$ & $2(03.7)$ & 0 & $02(01.5)$ \\
\hline $81-90$ & 0 & $2(02.5)$ & $02(01.5)$ \\
\hline Total & $54(100.0)$ & $81(100.0)$ & 135 \\
\hline \multicolumn{4}{|c|}{$\begin{array}{c}\text { Table 1. Age and Sex-Wise distribution of Patients with } \\
\text { Candidiasis }\end{array}$} \\
\hline
\end{tabular}

$* \mathrm{P}=0.003,{ }^{* *} \mathrm{P}=0.023,{ }^{* * *} \mathrm{P}=0.000$

\begin{tabular}{|c|c|c|}
\hline Sample & $\begin{array}{l}\text { Number of Candida } \\
\text { Species Isolated }\end{array}$ & Percentage \\
\hline Urine & 49 & 36.3 \\
\hline Vaginal Swab & 25 & 18.5 \\
\hline Sputum & 23 & 17.0 \\
\hline Wound Swab & 16 & 11.9 \\
\hline Blood & 12 & 08.9 \\
\hline Oral Swab & 06 & 04.4 \\
\hline Aural Swab & 04 & 03.0 \\
\hline Total & 135 & 100.0 \\
\hline
\end{tabular}

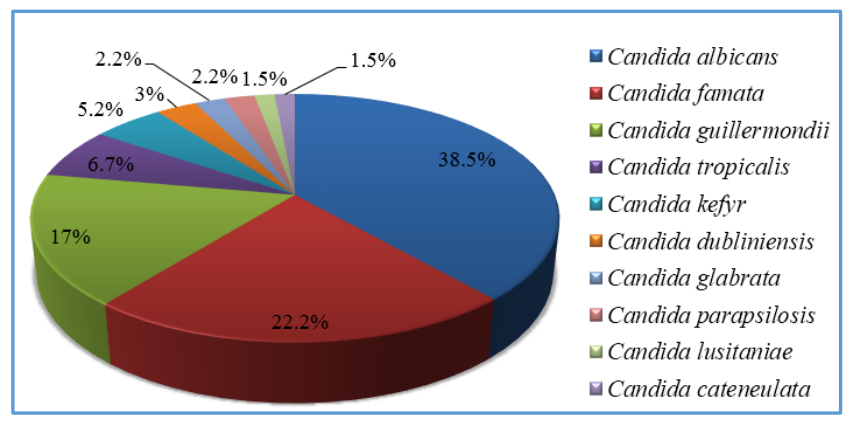

Figure 1. Candida Species Isolated from different Clinical Samples

\begin{tabular}{|c|c|c|c|}
\hline Antibiotic & $\begin{array}{c}\text { Sensitive } \\
(\%)\end{array}$ & $\begin{array}{c}\text { Resistant } \\
(\%)\end{array}$ & $\begin{array}{c}\text { Dose } \\
\text { Dependent (\%) }\end{array}$ \\
\hline Voriconazole & $38(73.1)$ & $14(26.9)$ & 0 \\
\hline Fluconazole & $33(63.5)$ & $18(34.6)$ & $01(5.2)$ \\
\hline Amphotericin B & $32(61.5)$ & $17(32.7)$ & $03(5.7)$ \\
\hline Itraconazole & $23(44.2)$ & $05(9.6)$ & $24(46.1)$ \\
\hline Ketoconazole & $13(25)$ & $21(40.4)$ & $18(34.61)$ \\
\hline Miconazole & $13(25)$ & $27(51.9)$ & $12(23.1)$ \\
\hline Nystatin & $04(7.7)$ & $08(15.4)$ & $40(76.9)$ \\
\hline \multicolumn{4}{|c|}{ Table 3. Antifungal Susceptibility Pattern } \\
of Candida albicans \\
\hline
\end{tabular}

\begin{tabular}{|c|c|c|c|}
\hline Antibiotic & $\begin{array}{c}\text { Sensitive } \\
(\%)\end{array}$ & $\begin{array}{c}\text { Resistant } \\
(\%)\end{array}$ & $\begin{array}{c}\text { Dose } \\
\text { Dependent (\%) }\end{array}$ \\
\hline Voriconazole & $70(84.3)$ & $13(15.7)$ & 0 \\
\hline Amphotericin B & $59(71.1)$ & $5(06.0)$ & $19(22.9)$ \\
\hline Fluconazole & $54(65.1)$ & $21(25.3)$ & $8(09.6)$ \\
\hline Itraconazole & $35(42.2)$ & $12(14.4)$ & $36(43.4)$ \\
\hline Ketoconazole & $18(21.7)$ & $39(47.0)$ & $26(31.3)$ \\
\hline Miconazole & $12(14.4)$ & $55(66.3)$ & $16(19.3)$ \\
\hline Nystatin & $12(14.4)$ & $12(14.4)$ & $59(71.0)$ \\
\hline \multicolumn{4}{|c|}{ Table 4. Antifungal Susceptibility Pattern of Non-Albicans } \\
Candida Species \\
\hline
\end{tabular}

\section{DISCUSSION}

Candida species was isolated in $62.6 \%$ of males and $37.3 \%$ of females in a study conducted in Andhra Pradesh. ${ }^{20}$ Also, another study from North-East India reported greater number of isolation of candida from males $62 \%$ in a study group that included patients from ICU. ${ }^{21}$ In the present study, however, $60 \%$ of strains were isolated from females.

Although, a fairly good number of Candida famata (33.3\%) and Candida guilliermondii (17.4\%), isolates produced germ tubes, maximum number of strains producing germ tubes was seen with Candida dubliniensis $(100 \%)$ and Candida albicans (96.2\%). Chlamydospore formation was seen mostly in Candida albicans and in few strains of Candida famata and Candida guilliermondii.

Different media for germ tube production of C. albicans and C. dubliniensis was ascertained by some workers who found that $90 \%$ of C. dubliniensis isolates produced germ tube in trypticase soy broth and pooled human serum, while in horse serum only $87.7 \%$ of isolates showed germ tube formation. As for C. albicans, germ tube production was seen in $98.5 \%$ of isolates in trypticase soy broth and $93.9 \%$ in pooled human serum and horse serum. ${ }^{22}$

Voriconazole was found to be the most useful antifungal drug against Candida albicans and non-albicans candida species as determined by the by disc-diffusion method. Dose dependent sensitivity was highest with nystatin, a polyene antifungal agent. Maximum resistance was seen against triazoles such as miconazole and ketoconazole.

Other workers have reported maximum sensitivity to amphotericin B (91\%) followed by voriconazole (65\%) and itraconazole (49\%). ${ }^{2}$ A few workers also reported that $78 \%$ of C. albicans were sensitive to fluconazole sensitivity to nystatin and amphotericin B was $100 \%$, a finding quite different from the present study. 23

Candida species was isolated most frequently from urine samples followed by vaginal swab and sputum. Amongst the candida species, Candida albicans was the most frequently 
isolated species in contrast to findings in other places in India where Candida tropicalis is the commonest.

Candida famata, a rare candida species was isolated as the most common non-albicans candida species. Candida famata (previously known as Debaryomyces hansenii) is a commensal yeast found in cheese, dairy products and the environment. It has been described in human infections including catheter-related infections, bloodstream infections, peritonitis, acute zonal occult retinopathy and mediastinitis. Though reported from other parts of India, the number of isolations of Candida famata was very few as compared to the present study. Direct microscopy of samples gave better results with $10 \% \mathrm{KOH}$ preparation than Gram staining. Sugar assimilation test was found to be the best method for speciation of candida isolates. However, for Candida albicans the germ tube test was found to be as efficacious as sugar assimilation test.

\section{CONCLUSION}

The incidence of the various fungal pathogens has increased dramatically over the past few decades. Candida species is the commonest of these fungal pathogens. These infections are often severe, rapidly progressive, difficult to diagnose and refractory to therapy.

C. albicans was previously responsible for nearly $80 \%$ of candidaemia in many hospitals. However, in recent years there has been a shift in the distribution of infections with non-albicans candida species being increasingly detected. In the present study, candida species were isolated more in young adult females who were in age group of 21 - 30 years.

Majority of males were young children in the age group of 1 - 10 years. Candida albicans, the germ tube test was found to be as efficacious as sugar assimilation test. The high occurrence of Candida famata in this region, however, needs to be investigated further with a larger patient population. Candida species was isolated most frequently from urine samples followed by vaginal swab and sputum. In present study, Candida albicans was the most frequently isolated species in contrast to findings in other places in India where Candida tropicalis is the commonest.

Candida famata, a rare candida species was isolated as the most common non-albicans candida species. Candida famata (previously known as Debaryomyces hansenii) is a commensal yeast found in cheese, dairy products and the environment. It has been described in human infections including catheter-related infections, bloodstream infections, peritonitis, acute zonal occult retinopathy and mediastinitis. Though reported from other parts of India, the number of isolations of Candida famata was very few as compared to our study.

\section{REFERENCES}

[1] Kothavade RJ, Kura MM, Valand GA, et al. Candida tropicalis: its prevalence, pathogenicity and increasing resistance to fluconazole. J Med Microbiol 2010;59(Pt 8):873-80.

[2] Roy RC, Sharma GD, Burman SR, et al. Trend of Candida infection and antifungal resistance in a tertiary care hospital of north east India. African Journal of Microbiology Research 2013;7(24):31123116.
[3] Chander J. Candidiasis. In: Chander J, ed. Textbook of mycology. $3^{\text {rd }}$ edn. New Delhi: Jaypee Brothers Medical Publishers 2008:266-90.

[4] Wisplinghoff $\mathrm{H}$, Bischoff $\mathrm{T}$, Tallent SM, et al. Nosocomial bloodstream infections in US hospitals: analysis of 24,179 cases from a prospective nationwide surveillance study. Clin Infect Dis 2004;39(3):309-17.

[5] Marchetti O, Bille J, Fluckiger U, et al. Epidemiology of candidemia in Swiss tertiary care hospitals: secular trends, 1991-2000. Clin Infect Dis 2004;38(3):311-20.

[6] Yapar N. Epidemiology and risk factors for invasive candidiasis. The Clin Risk Manag 2014;10:95-105.

[7] Sievert DM, Ricks P, Edwards JR, et al. Antimicrobialresistant pathogens associated with healthcareassociated infections: summary of data reported to the national healthcare safety network at the Centers for Disease Control and Prevention, 2009-2010. Infect Control Hosp Epidemiol 2013;34(1):1-14.

[8] Magill SS, Shields C, Sears CL, et al. Triazole crossresistance among candida spp.: case report, occurrence among bloodstream isolates, and implications for antifungal therapy. J Clin Microbiol 2006;44(2):529-35.

[9] Xess I, Jain N, Hasan F, et al. Epidemiology of candidemia in a tertiary care centre of north India: 5year study. Infection 2007;35(4):256-9.

[10] Kothari A, Sagar V. Epidemiology of candida bloodstream infections in a tertiary care institute in India. Indian J Med Microbiol 2009;27(2):171-2.

[11] Shivaprakasha S, Radhakrishnan K, Karim PM. Candida spp. other than candida albicans: a major cause of fungaemia in a tertiary care centre. Indian J Med Microbiol 2007;25(4):405-7.

[12] Chakrabarti A, Chatterjee SS, Rao KL, et al. Recent experience with fungaemia: change in species distribution and azole resistance. Scand J Infect Dis 2009;41(4):275-84.

[13] Kett DH, Azoulay E, Echeverria PM, et al. Candida bloodstream infections in intensive care units: analysis of the extended prevalence of infection in intensive care unit study. Crit Care Med 2011;39(4):665-70.

[14] Azoulay E, Dupont H, Tabah A, et al. Systemic antifungal therapy in critically ill patients without invasive fungal infection. Crit Care Med 2012;40(3):813-22.

[15] Arendrup MC, Sulim S, Holm A, et al. Diagnostic issues, clinical characteristics, and outcomes for patients with fungemia. J Clin Microbiol 2011;49(9):3300-8.

[16] Lark RL, Chenoweth C, Saint S, et al. Four year prospective evaluation of nosocomial bacteremia: epidemiology, microbiology, and patient outcome. Diagn Microbiol Infect Dis 2000;38(3):131-40.

[17] Gudlaugsson O, Gillespie S, Lee K, et al. Attributable mortality of nosocomial candidemia, revisited. Clin Infect Dis 2003;37(9):1172-7.

[18] Procop WG, Church LD, Hall GS, et al. Mycology. In: Procop WG, ed. Koneman's color atlas and textbook of diagnostic microbiology. $7^{\text {th }}$ edn. Philadelphia: Wolters Kluwer Health 2017:1322-416. 
[19] Ghosh A, Shivaprakash MR, Chakraborty A, et al. Standard Operating Procedures: National Antifungal Resistance Surveillance. ICMR 2015:1-36.

[20] Shaik N, Penmetcha U, Myneni RB, et al. A study of identification and antifungal susceptibility pattern of candida species isolated from various clinical specimens in a tertiary care teaching hospital, Chinakakani, Guntur, Andhra Pradesh, south India. Int J Curr Microbiol App Sci 2016;5(7):71-91.

[21] Dutta V, Lyngdoh WV, Bora I, et al. Characterization of candida species from intensive care unit isolates in a tertiary care centre in north-east India: a retrospective study. Int J Med Public Health 2015;5(4):312-6.
[22] Deorukhkar CS, Saini S, Mathew S. Virulence factors contributing to pathogenicity of candida tropicalis and its antifungal susceptibility profile. International Journal of Current Microbiology and Applied Sciences 2014;3(1):206-18.

[23] Gandhi NT, Patel MG, Jain RM. Antifungal susceptibility of candida against six antifungal drugs by disk diffusion method isolated from vulvovaginal candidiasis. Int J Cur Res Rev 2015;7(11):20-5. 